Int. J. Electrochem. Sci., 13 (2018) $7045-7056$

\title{
Copper/Iron Composite Anode prepared by in situ co- precipitation with Excellent High-rate and Low-temperature Performance for Rechargeable Nickel-Iron Battery
}

\author{
Lanxiang Huang ${ }^{1}$, Jun Yang ${ }^{1}$, Ping Liu ${ }^{1}$, Ding Zhu ${ }^{2, *}$, Yungui Chen ${ }^{1,2, *}$ \\ ${ }^{1}$ Department of Advanced Energy Materials, College of Materials Science and Engineering, Sichuan \\ University, Chengdu 610065, PR China \\ ${ }^{2}$ Institute of New Energy and Low-Carbon Technology, Sichuan University, Chengdu 610065, PR \\ China \\ "E-mail: ygchen60@aliyun.com; zhuding@scu.edu.cn
}

doi: $10.20964 / 2018.07 .80$

Received: 27 March 2018 / Accepted: 21 May 2018 / Published: 5 June 2018

Copper/iron composite anode materials were synthesized by one-step co-precipitation method followed by calcination at high temperature in this paper, which had shown excellent high-rate discharge capacity and low temperature capability. Even the discharge-rate is as high as $10 \mathrm{C}$ (1 C=200 $\mathrm{mA} \mathrm{g}{ }^{-1}$ ), or the temperature is as low as $253 \mathrm{~K}$, the batteries still exhibited good discharge capacity (130 $\mathrm{mA} \mathrm{h} \mathrm{g}^{-1}$ and $115 \mathrm{~mA} \mathrm{~h} \mathrm{~g}^{-1}$, respectively). XRD and SEM results revealed that under the reduction treatment of acetylene carbon black at high temperature, copper atoms were preferentially reduced, removed from the spinel lattice and deposited on the surface, leading to the formation of porous structure with high specific surface. EIS and polarization tests proved that the copper/iron composite anode materials not only delayed the passivation but also raised the hydrogen evolution overpotential, both improved the dynamics of the iron electrode.

Keywords: copper/iron composite anode, excellent high-rate discharge capacity, low temperature performance, Nickel-Iron battery

\section{$\underline{\text { FULL TEXT }}$}

(C) 2018 The Authors. Published by ESG (www.electrochemsci.org). This article is an open access article distributed under the terms and conditions of the Creative Commons Attribution license (http://creativecommons.org/licenses/by/4.0/). 